International Journal of Reproduction, Fertility \& Sexual Health (1JRFSH)

ISSN: 2377-1887

\title{
Acardiac Acephalus Twin and Associated Anomalies: A Case Report
}

Juhi Godara

General \& Family Physician, King George Medical University, Ahmedabad, Gujarat, India.

\section{Abstract}

A 30-year-old multipara was found to carry an acardiac acephalus twin in a monozygotic twin pregnancy at 24 weeks of gestation and was referred to us from a private clinic. A cardiac twinning, a rare congenital anomaly of monozygotic twin pregnancy, often results from abnormal placental vascular anastomosis. Acardiac acephalus is a acardiac twin lacking a head, though it may have arms; thoracic organs are generally absent, and disorganized \& unidentifiable tissues take their place, which invariably leads to death of the "perfused" twin and an estimated 50\% perinatal mortality rate in the "pump" twin, due mainly to premature delivery or congestive heart failure. Autopsy of the fetus showed abnormalities compatible with the maldevelopment of embryonic folding. Fetus had omphalocele, bilateral absent kidneys, dextrocardia, hypoplastic lungs, absent right radial bone, abnormally positioned ears and agnathia.

Keywords: Acardiac Acephalus; Omphalocele, Dextrocardia.

\section{*Corresponding Author:}

Dr. Juhi Godara, M.B.B.S., M.D,

General and Family Physician, King George Medical University,

Ahmedabad, Gujarat, India.

Tel: 09429109894

E-mail: drjuhigodara@gmail.com

Received: September 08, 2015

Accepted: December 04, 2015

Published: December 07, 2015

Citation: Juhi Godara (2015) Acardiac Acephalus Twin and Associated Anomalies: A Case Report. Int J Reprod Fertil Sex Health, 2(4) 54-56. doi: http://dx.doi.org/10.19070/2377-1887-1500010

Copyright: Juhi Godara $^{\circledR}$ 2015. This is an open-access article distributed under the terms of the Creative Commons Attribution License, which permits unrestricted use, distribution and reproduction in any medium, provided the original author and source are credited.

\section{Introduction}

Acardiac twinning is thought to affect 1 in 100 monozygotic twin pregnancies and 1 in 35,000 pregnancies overall $[1,2]$. There is no recognised familial recurrence. An acardiac twin can present with four morphological types:

A. Acardius anephus: Most common type. There is absence of the head and upper torso and limbs in the acardiac twin with preservation of the lower limbs, genitalia and abdominal viscera.

B. Acardius anceps. Most developed type. Rudimentary cranial structures present with otherwise persistent trunk, limbs and organs however lacks even a rudimentary heart.

C. Acardius Amorphus: Least differentiated type, comprises of an amorphous mass of bone, muscle, fat and connective tissue if rudimentary nerve tissue is present, it is then called acardius myelantencephalus.

D. Acardius Acormus: Rarest type. The only developed struc- ture is the fetal head $[3,4]$.

This type of with twinning is associated with single umbilical artery: $\sim 66 \%$ and underlying chromosomal anomaly: $33 \%$ [5]. The other donor (pump) twin may develop cardiac failure (hydrops) with a reported mortality of $50-75 \%$ and $100 \%$ mortality in recipient twin [6].

In this case, we presented a patient $\mathrm{G}_{4} \mathrm{P}_{3+0}(1 \mathrm{~A} \& \mathrm{H}) 24$ weeks pregnancy with multiple congenital anomalies in fetus with previous 3 LSCS with 2 antepartum stillbirths with history of anencephaly in one fetus.

\section{Case Report}

A 30-year-old multipara with 24 weeks pregnancy was referred to department of obstetrics, KGMU in view of multiple anomalies in fetus. Routine antenatal investigations done and second trimester ultrasonography showed a viable intrauterine pregnancy of 22 weeks GA with deformed fetal spine with scoliosis with dilated fetal ventricles with omphalocele with liver herniation with severe oligohydramnios.

Figure 1. Acardiac acephalus twin showing omphalocele with herniated bowel loops and liver.

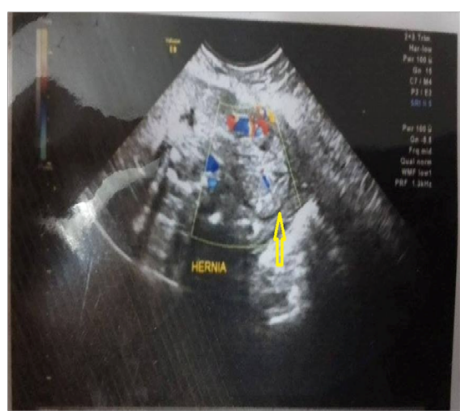


In view of multiple congenital anomalies and history of previous 3 caesarean sections, patient was posted for caesarean section under spinal anaesthesia on 19/8/2015. Fetus delivered was twin (acardiac acephalus), which expired soon after birth. Fetus was thoroughly examined and sent for autopsy.

Placenta of the twin was monochorionic monoamniotic, discoid and 242 grams with the cord inserted centrally. Umbilical cord had only one vein and 2 arteries. Fetus was 24 weeks gestational age with $\mathrm{CRL}=19 \mathrm{~cm}$ and $\mathrm{CHL}=24 \mathrm{~cm}$.

Twin A (the pump twin) and twin B (the acardiac twin) were in a breech presentation, with grossly abnormal anatomy consistent with 24 weeks. There was hypotelorism, abnormally placed ears, hypoplastic nose and oromandibular hypoplasia in the head.

\section{Figure 2. Acardiac acephalus twin delivered at 24 weeks Pregnancy.}

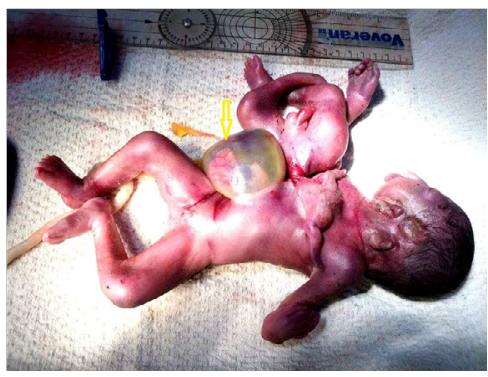

Abdomen displayed an omphalocele formed from an outpouching of peritoneum, protruding in the midline, through the umbilicus. Pump twin displayed deformities in left upper limb and anus was not visible and no discernible external genitalia were noted.

Figure 3. Acardius acephalus twin showing oromandibular hypoplasia with abnormally positioned ears.

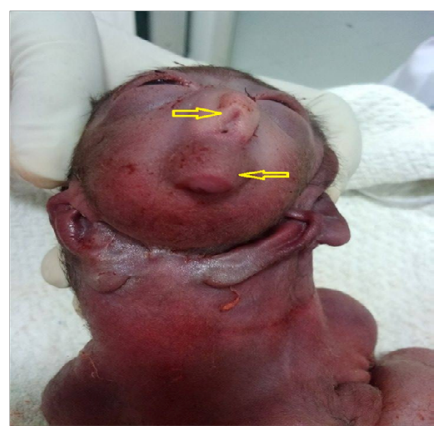

Figure 4. Radiograph of acardius acephalus showing absence radius in left forearm of pump twin and absent pelvic bone in acardiac twin.

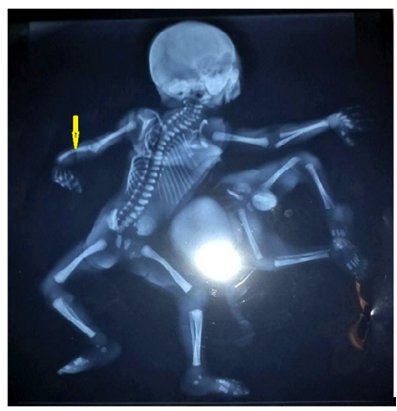

Acardiac twin was attached to pump twin in thoracic region and had absent head and disorganized thorax and lower limbs with herniating abdominal viscera in omphalocele.

On autopsy, hypertrophied dextrocardia and right sided hypoplastic lung with 3 lobes in right and 2 in left lung in the thorax and no identifiable genitourinary structures. On dissecting the peritoneum of omphalocele, two separate liver, two separate spleen and small and large intestines were identified.

Figure 5. Acardiac acephalus twin showing contents of omphalocele (two separate liver and two separate spleens with bowel loops).

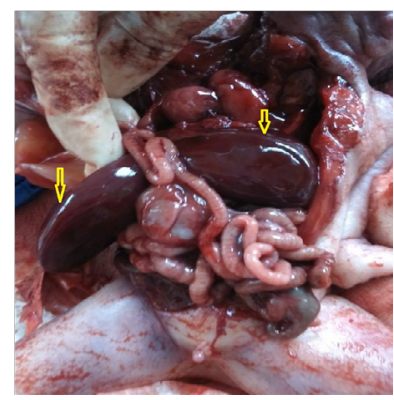

\section{Discussion}

Acardiac twinning is a rare congenital anomaly characterized by formation of a malformed fetus with an absent or rudimentary (but nonfunctional) heart. A variety of acardiac twins have been described based on the degree of cephalic and truncal maldevelopment. The acardiac-acephalus fetus has no cephalic development. Acardiac anomaly usually occurs in monozygotic twins, although there are a few reports of dizygotic twins with a fused placenta. It is more common in female twins, and because the disorder is monozygotic, the twins are usually of same gender.

An acardiac twin should be suspected in all monochorionic, malformed fetuses with cystic hygroma, generalized edema, and an absent cardiac pulsation with a nonfunctioning heart. Similarly, an ultrasonography finding of twins revealing discordant or grotesque malformation along with reverse flow in the umbilical artery is usually diagnostic of an acardiac twin [7].

It is normal for the intestines to protrude from the abdomen, into the umbilical cord, until about the tenth week of pregnancy, after which they return to inside the fetal abdomen. Omphalocele is a type of abdominal wall defect in which the intestines, liver, and occasionally other organs remain outside of the abdomen in a sac because of a defect in the development of the muscles of the abdominal wall (exomphalos). Larger omphalocele are associated with a higher risk of cardiac defects [8]. Omphalocele occurs in $2.5 / 10,000$ births and is associated with a high rate of mortality $(25 \%)$ and severe malformations, such as cardiac anomalies $(50 \%)$ and neural tube defect $(40 \%)$. Approximately $15 \%$ of live-born infants with omphalocele have chromosomal abnormalities $[3,9]$.

\section{Conclusion}

In conclusion, diagnosis of acardiac twin can be made in the first trimester itself by USG and Doppler. Early diagnosis of chronicity of twin pregnancy helps in improving the survival of the pump twin. Prevention of preterm labor and diagnosing cardiac failure in the pump twin is very important. Treatment at appropriate time 
improves the survival of the pump twin by $95 \%$ with an average age at delivery between 36 and 37 weeks.

\section{References}

[1]. Rohilla M, Chopra S, Suri V, Aggarwal N, Vermani N (2008) AcardiacAcephalus Twins: A Report of 2 Cases and Review of Literature. Medscape J Med 10(8): 200.

[2]. Law KS, Chang SD, Chen FP, Soong YK (1999) Acardiac acephalus: a case report and implications on expectant management. Chang Gung medical journal 22(2): 334-338.

[3]. Moore TR, Gale S, Benirschke K (1990) Perinatal outcome of forty-nine pregnancies complicated by acardiac twinning. Am J Obstet Gynecol 163(3): 907-912.
[4]. Sepúlveda WH, Quiroz VH, Giuliano A, Henríquez R (1993) Prenatal ultrasonographic diagnosis of acardiac twin. J Perinat Med 21(3): 241-246.

[5]. Wong AE, Sepulveda W (2005) Acardiac anomaly: current issues in prenatal assessment and treatment. Prenat Diagn 25(9): 796-806.

[6]. Hrubec Z, Robinette CD (1984) The study of human twins in medical research. N Engl J Med 310(7): 435-441.

[7]. Chen CP, Shih SL, Liu FF, Jan SW, Lin YN, et al. (1997) Skeletal deformities of acardius anceps: The gross and imaging features. Pediatr Radiol 27(3): 221-225.

[8]. Hanafy A, Peterson CM (1997) Twin-reversed arterial perfusion (TRAP) sequence: case reports and review of literature. Aust $N$ Z J Obstet Gynaecol 37(2): 187-191.

[9]. Stamatian F, Muresan D, Caracostea G, Kovacs T (2011) Advances in ultrasonic assessment of acardiac twin. Donald Sch J Ultrasound Obstet Gynecol 5(3): 213-218. 